\title{
SUBSURFACE THERMAL ENVIRONMENT CHANGE DUE TO ARTIFICIAL EFFECTS IN THE TOKYO METROPOLITAN AREA, JAPAN
}

Akinobu Miyakoshi*, Takeshi Hayashi**, Masafumi Kawai ${ }^{\star \star \star}$, Shinichi Kawashima ${ }^{\star \star \star}$, Shoichi Hachinohe ${ }^{\star \star \star \star}$ *Geological Survey of Japan, AIST, Tsukuba, Japan; ${ }^{\star *}$ Akita University, Akita, Japan; ${ }^{\star * \star}$ Civil Engineering Center, Tokyo Metropolitan Government, Tokyo, Japan; ${ }^{* * *}$ Center for Environmental Science in Saitama, Saitama, Japan

\begin{abstract}
Information on three-dimensional distribution of subsurface temperature was examined to evaluate the effect of heat island phenomena on the subsurface thermal environment beneath the Tokyo Metropolitan Area, Japan. Subsurface temperature distribution shows regional difference according to depths. At the depth of $50 \mathrm{~m}$, high temperatures were located from the eastern part of the Musashino Upland and the western part of the Tokyo Lowland, and low temperatures were located in the central-western part of the upland. The high temperature area corresponds with the city centre and its circumstance, and heat island phenomena were found in the subsurface environment. Moreover, subsurface warming was found from the changes of temperature-depth profiles in the recent 15 years. Temperatures in 2005-2008 show higher warming ratio than 1991-2001, and the warming area is expanding toward the suburban area until 2008. Results of long-term monitoring in 2007-2008 also advocate tendency of surface warming. These facts suggest that the urban subsurface heat island is progressing beneath the Tokyo Metropolitan Area.
\end{abstract}

Key words: urban subsurface heat island, subsurface temperature, groundwater flow, urban subsurface environment, urbanization, Tokyo Metropolitan Area

\section{INTRODUCTION}

Subsurface temperature data preserve a record of past ground surface temperature change. Potential to reconstruct the past ground surface temperature environment through the use of an inverse analysis of temperature-depth profiles has been shown by some existing studies (Pollack et al., 2000), and the subsurface temperature data has been recognized as a useful indicator for environmental assessments. Reasons for recent ground surface warming are mainly considered effects of global warming and urbanization. The warming of $0.74 \pm 0.18 \mathrm{~K}$ was estimated as the global warming over the last 100 years (IPCC 2007). However, a temperature increase of about $2.9 \mathrm{~K}$ was shown in the last 100 years in the city centre of Tokyo (Japan Meteorological Agency, 2007). Likewise, the temperature increases several times the rate of the global warming has been reported in many cities of the world. This fact suggests that the effects of urbanization on the local scale are stronger than the global warming.

Effects of the ground surface warming due to the combined effects of global warming and urbanization are comprehended as a temperature increase in the subsurface environment. Subsurface temperature is affected by not only heat conduction but also advection due to groundwater flow (Anderson, 2005). Hence, effects of the ground surface warming reaches to the deep part due to the downward groundwater flow in the groundwater recharge area, and the effects are sequestered in the shallow part of the discharge area.

Some studies on subsurface temperature distribution affected by groundwater flow and ground surface temperature change have been carried out (Ferguson and Woodbuy, 2005; Majorowiwicz et al., 2006). The magnitude of these effects shows regional difference due to the difference of geothermal, geological, hydrological and surface environmental conditions.

The purpose of this study is the evaluation of effects of heat island phenomena on the subsurface thermal environment beneath the Tokyo Metropolitan Area. Tokyo has a population of almost 12 million, and is one of the most urbanized areas in the world. The temperature data shows that warming tends progress quickly. The data also shows the temperatures difference between the city centre and suburban area, and this fact suggests the heat island phenomena exist in Tokyo. We expected to find heat island phenomena in the distribution of subsurface temperature.

\section{STUDY AREA AND OBSERVATION METHOD OF SUBSURFACE TEMPERATURE DATA}

This study area is the Tokyo Metropolitan Area, which is located from the foot of Kanto Mountain in the west to Tokyo Bay, the Shimofusa Upland on the east and the north side of the Tama River (Fig. 1). This study area is divided into two geomorphological regions, the

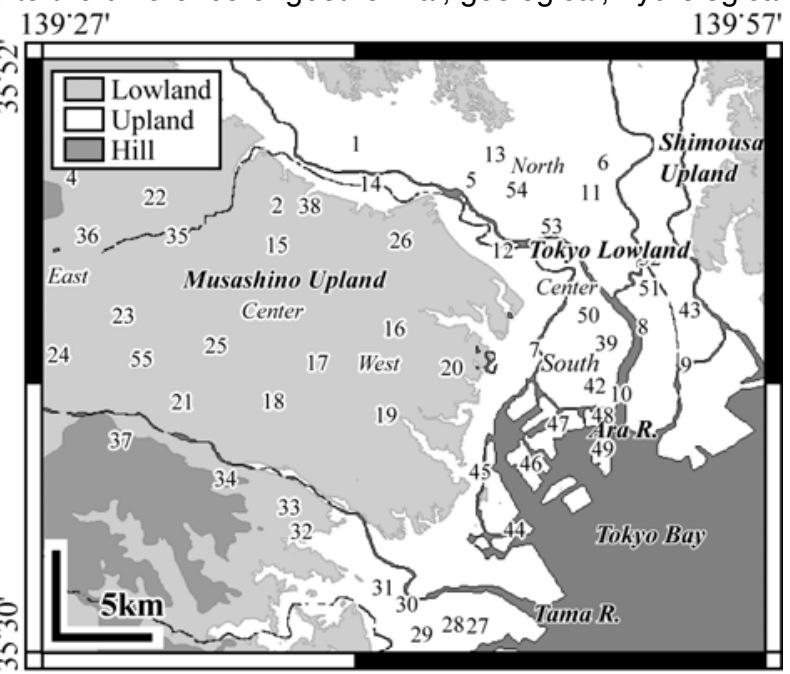

Fig. 1 Study area Tokyo Lowland in the east and the Musashino Upland 
in the west. The Musashino Upland is covered by relatively permeable volcanic ash which is named the Kanto loam, with a thickness of $5-10 \mathrm{~m}$. The Upland is underlain by terrace gravel found in the Tachikawa and Musashino Beds, and the Kazusa Formation. Kazusa Formation is mainly subdivided, in decreasing order, into the Toneri Beds consisting of intercalated silt, sand, and gravel, the sand-rich Higashikurume Bed, and the Kitatama Bed consisting mostly of indurated silt. The Tokyo Lowland is underlain by alluvium, the Tokyo Formation, and the Kazusa Formation in descending order. The beds lower than the alluvium slope to the east from the Musashino Upland toward the Lowland resulted in thicker Tokyo Beds in the east. Aquifers of this area are alluvium, the Tokyo Formation, and the Edogawa, Toneri, and Higashikurume Beds of the Kazusa Formation. The upper surface of indurated silt of the Kitatama Bed seems to form the bottom of the aquifer.

Subsurface temperature data was observed as temperature-depth profiles at 56 observation wells (\#1 to \#56, Fig. 1). Well diameters are $10-25 \mathrm{~cm}$ (mostly $15 \mathrm{~cm}$ ), and depths range between 56 and $450 \mathrm{~m}$. Measurements of temperature-depth profiles were carried out at these wells by using thermistor thermometer with a resolution of $0.01 \mathrm{~K}$. Additionally, long-term monitoring of subsurface temperature was started from 2007 at \#5. Highresolution thermometers $(0.001 \mathrm{~K})$ have been installed to evaluate precision temperature change.

\section{OBSERVATION RESULTS AND DISCUSSION 3.1. Regional characteristics of subsurface temperature distribution}

Distributions of subsurface temperatures in the plane are shown in Fig. 2 (after Miyakoshi et al, 2008). The distribution at the depth of $50 \mathrm{~m}$ (Fig.
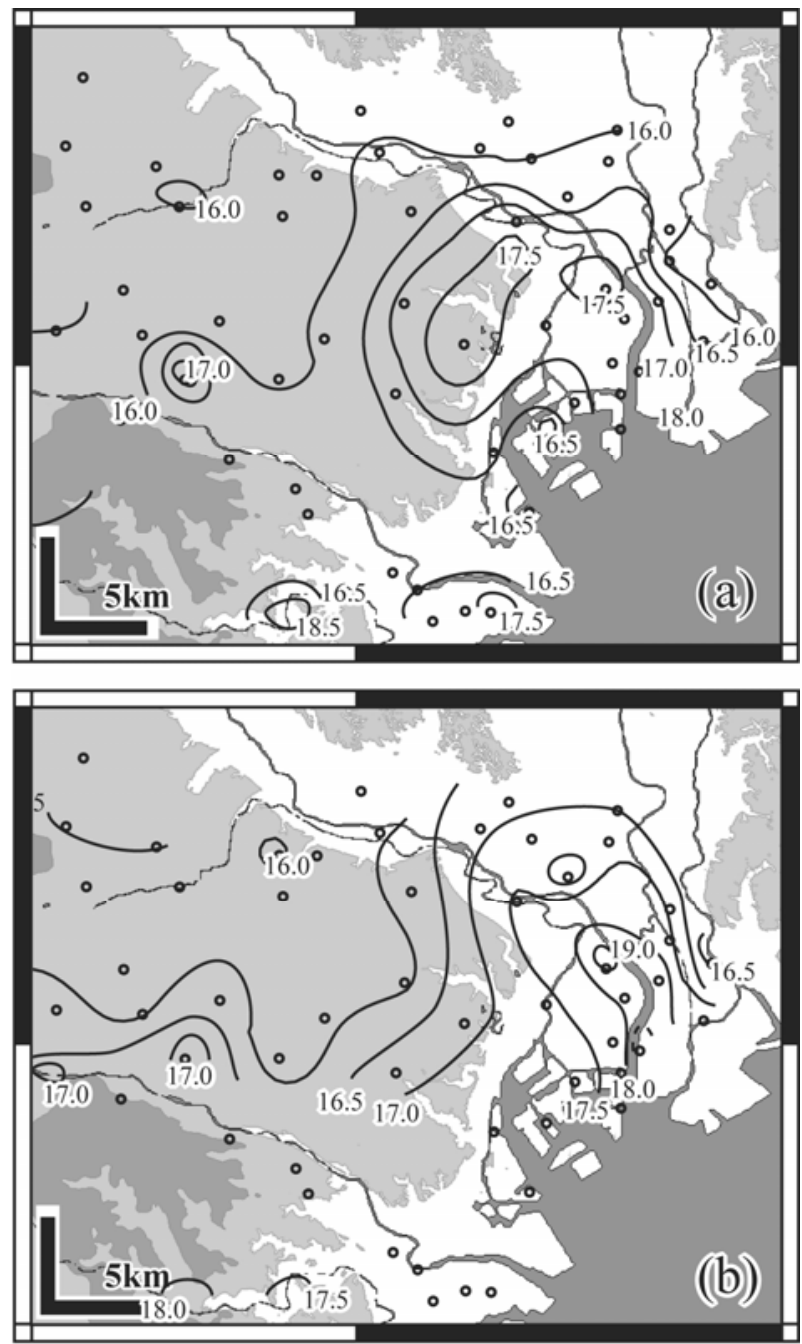

Fig. 2 Distribution of subsurface temperature at the denths of $50 \mathrm{~m}$ (a) and $100 \mathrm{~m}(\mathrm{~h})$

2(a)) shows high temperatures greater than $17.0^{\circ} \mathrm{C}$ from the eastern part of the Musashino Upland to the centralsouthern part of the Tokyo Lowland and the mouth of the Tama River. Temperatures were particularly high at \#20 $17.9{ }^{\circ} \mathrm{C}$ in the eastern part of the Upland and at \#50 $17.8{ }^{\circ} \mathrm{C}$ in the central part of the Lowland. \#7, which is located between \#20 and \# 50, has comparatively low temperature of $17.1^{\circ} \mathrm{C}$. This divides the high temperature areas at \#20 and \#50 on an east-west line. On the other hand, low temperatures less than $16.0^{\circ} \mathrm{C}$ were recorded in the eastern part of the Upland and the northern part of the Lowland. Fig. 2(b). shows the distribution at the depth of $100 \mathrm{~m}$. High temperatures greater than $17.5^{\circ} \mathrm{C}$ were found in the central-southern part of the Lowland, and \#50 had the remarkable high temperature of $19.1{ }^{\circ} \mathrm{C}$. Meanwhile, low temperatures less than $16.5^{\circ} \mathrm{C}$ were located in the central-western part of the Upland. In the comparison to the depth of $50 \mathrm{~m}$, high temperatures around \#20 in the eastern part of the Upland disappeared. The low temperature area consisting of reading under $16.5^{\circ} \mathrm{C}$ extends from the western part to the central part of the Upland. The eastern part of the Upland forms the division between the low and high temperatures in the Low-land.

\subsection{Relation between land use and heat island phenomena in the subsurface environment}

Fig. 3 . is the land-use map of the study area in 1997. In light of land coverage, land utilizations were classified into 3 types, paved area (business, industrial and residential district and roads), unpaved area (agricultural area, parks, wood and forest land) and others. Distribution of the paved area is dense in the urban area from the eastern part of the Upland to the Lowland. The proportion of the unpaved area gradually increases from the central part to western part of the Upland where are defined as the suburban area. From the subsurface temperature distribution at depth of $50 \mathrm{~m}$, high temperatures greater than $17.0^{\circ} \mathrm{C}$ were located in the paved area. Low temperatures less than $16.0^{\circ} \mathrm{C}$ were located in the sub-urban area which has a high proportion of unpaved area. This tendency of subsurface temperature distribution shows the heat island phenomena in the subsurface environment, in which the center of high temperature is located from the eastern part of the Upland to the Lowland. 
Isopleths in Fig. 3 show the depth of minimum temperature (after Miyakoshi et al, 2008). Effects of ground surface warming are relatively greater at the part between ground surface and the minimum temperature depth than below the depth of minimums, and the depths indicates the beneath impact expansion of ground surface warming. In the Musashino Upland, the minimums occur deeper than the depth of $60 \mathrm{~m}$, especially at wells \#16 and \#20 they are over $80 \mathrm{~m}$. On the other hand they are shallower than $40 \mathrm{~m}$ deep in the Lowland. Distribution of the depth of minimum temperature is shown as a dotted line in the vertical distribution on Fig. 3. In comparison to the urban area (the eastern part of the Upland to the Lowland), the depths of minimum temperature were deeper in the suburban area, even though ground surface warming effects were smaller. Groundwater has been pumped at the rate of 0.5 million $\mathrm{m}^{3} /$ day in this area. Moreover, ground surfaces are unpaved in many regions (Fig. 3 ), and it is considered that the induced groundwater recharge was caused by the effects of pumping.

Therefore, minimums may be formed at the deep part by the effects of downward groundwater flow in this suburban area. This fact suggests the minimum depths are affected by local groundwater flow in addition to surface warming.

\subsection{Changes of temperature-depth profiles in the recent decade and results of long-term monitoring in 2007-2009}

Fig. 4. shows temperature-depth profiles at \#23 (Fig. 1). These were observed in 1991 (Dapaah-Siakwan and Kayane, 1995), 2001 and 2005. Temperature change between 1991 and 2001 is small and subsurface warming is found above the depth of $70 \mathrm{~m}$. In $2001-2005$, subsurface warming was shown higher than $0.1 \mathrm{~K}$ at the depth of $80 \mathrm{~m}$, and the warming reaches blow the depth of $100 \mathrm{~m}$.

Fig. 5 shows temperature-depth profiles at the well \#5 and subsurface temperature change at the depth of $30 \mathrm{~m}$ and $40 \mathrm{~m}$. Comparison of temperature-depth profiles shows warming of $0.1 \mathrm{~K}$ at $30 \mathrm{~m}$ from 2000 to 2008 . Longterm monitoring record in 2007-2008 also show warming at a rate of $0.025 \mathrm{~K} /$ year at the same depth.

These comparisons of past and recent temperature-depth profiles and long-term monitoring record show the progress of subsurface warming at the shallow part. These wells locate around the boundary/transition band between the urban and suburban area. These facts suggest that subsurface warming speed is increasing and extends the impact in recent years. We could find out that the urban subsurface heat island are progressing beneath the Tokyo Metropolitan Area, and this will continue in the future.

\section{CONCLUSION}

1) Distribution of subsurface temperature in the Tokyo Metropolitan Area shows the regional differences according to the depths. At the depth of $50 \mathrm{~m}$, high temperatures were located from the eastern part of the Upland to the Lowland, and low temperatures were located from the central to western part of the Upland. At the depth of $100 \mathrm{~m}$, high temperatures were only found in the central part of the Lowland, and the low temperatures area was expanded.

2) From the comparison between the land-use map and the distribution of subsurface temperature, urban subsurface heat island phenomena, the center of which was located around the eastern part of the Upland, were found beneath the Tokyo Metropolitan Area. The high temperatures in the eastern part of the Upland were mainly formed by ground surface warming effects, while high temperatures in the central part of the Lowland were formed by not only ground surface warming effects but also heat advection due to upward groundwater flow. 3) Effects of ground surface warming reach deeper in the central-western part of the Upland, even though the surface warming effects are small. Groundwater has been pumped in this suburban area, and ground surfaces have been un-paved in many regions. Therefore, it is considered that minimum

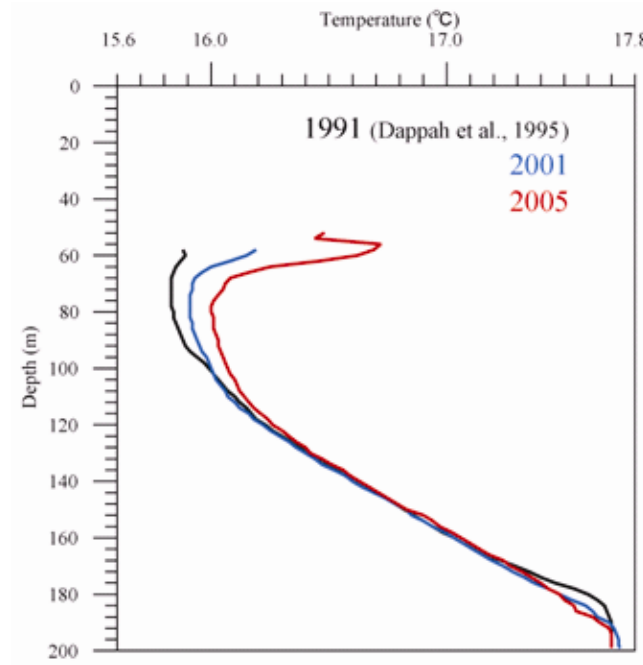

Fig. 4 Temperature-depth profiles at \#23 in 1991 (Dapaah-Siakwan and Kayane, 1995), 2001 and 2005. 
depths become deeper due to the induced downward groundwater flow.

4) Changes of temperature-depth profile during the recent 15 years show the existence of subsurface heat island phenomena. The subsurface warming ratio in 2001-2005 is higher than 1991-2001, and the impacts in 20012005 expand deeper than 1991-2001. Long-term monitoring record also shows warming tendency in 2007-2008. These facts suggest that the subsurface heat island is progressing beneath the Tokyo Metropolitan Area, and this will continue in the future.
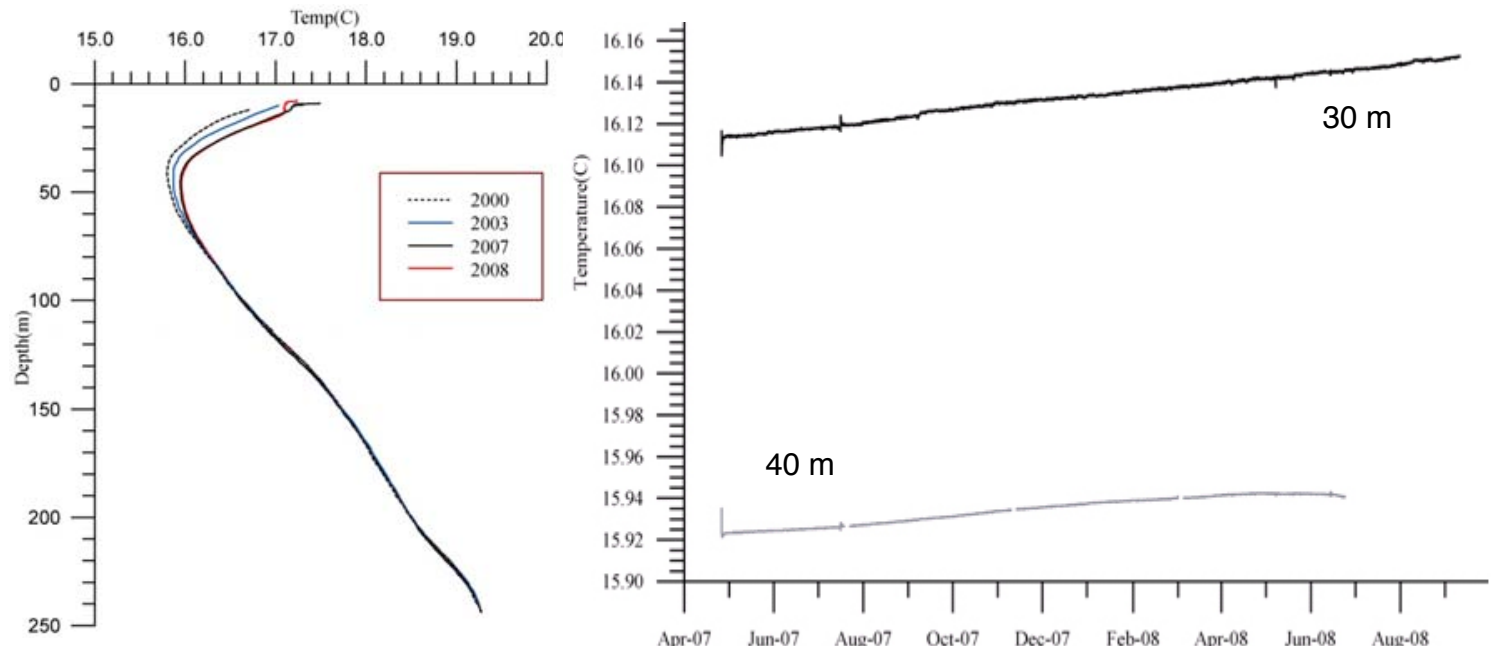

Fig. 5 (a) Temperature-depth profiles at \#5 in 2000, 2003, 2007 and 2008, (b) Long-term temperature records at \#5.

\section{References}

Anderson, M.P. (2005): Heat as a groundwater tracer, Ground Water, 43-6:951-968.

Dapaah-Siakwan, S. And Kayane, I. (1995): Estimation of vertical groundwater and heat flux in the semi-confined aquifers in Tokyo metropolitan area, Japan. Hydrological Processes, 9:143-160.

Ferguson,G. and Woodbuy, A. D. (2005) The effects of climatic variability on estimates of recharge from temperature profiles. Groundwater, 43-6:837-842

Geographical Survey Institute (1997): Digital Information of Land Use.

IPCC (2006) IPCC 2006 IPCC Guidelines for National Greenhouse Gas Inventories, Volume 1 General Guidance and Reporting.

Japan Meteorological Agency (2007): Climatic Statistics Data. http://www.data.jma.go.jp/.

Kawashima,S (2001) Groundwater environment in Tokyo, Journal of Japan Ground Water Technology Association, 43-3:6-19.

Majorowicz, J., Grasby, S. E., Ferguson, G., Safanda, J. and Skinner, W. (2006) Paleoclimatic reconstructions in western Canada from borehole temperature logs: surface air temperature forcing and groundwater flow, Climate of the Past, 2:1-10.

Miyakoshi, A., Hayashi, T., Marui, A., Sakura Y., Kawashima, S. and Kawai, M. (2006) Evaluation of change in groundwater environment by subsurface temperature in the Tokyo Lowland, Japan, Journal of Japanese Society of Engineering Geology, 47-5:269-279

Miyakoshi,A., Hayashi, T., Monyrath, V., Lubis, R. F., Sakura, Y. (2008) Subsurface thermal environment change due to artificial effects in the Tokyo metropolitan area, Japan, From Headwaters to the Ocean: Hydrological Change and Watershed Management, Talor \& Francis.

Pollack, H. N., Shauopeng, H. and Shen, P.-Y. (2000) Climate change record in subsurface tem-peratures: a global perspective, Science, 282:279-281. 